\title{
Theorising simulation in higher education: difficulty for learners as an emergent phenomenon
}

\author{
Madeleine Abrandt Dahlgren ${ }^{1}$, Tara Fenwick ${ }^{2}$ \& Nick Hopwood ${ }^{3}$
}

1. Madeleine Abrandt Dahlgren (corresponding author)

Dept of Medical and Health Sciences, Linköping University, SE-58183 Linköping, Sweden

Madeleine.abrandt.dahlgren@liu.se

$+4613282135$

2. Tara Fenwick

School of Education, University of Stirling,

Stirling FK9 4LA UK

Tara.fenwick@stir.ac.uk

+44 (0)1786 467611

3. Nick Hopwood

School of Education, University of Technology Sydney

P.O. Box 123, Broadway, NSW 2007, Australia

Nick.hopwood@uts.edu.au

+61295144658

The paper draws on research carried out in all three affiliations. 


\section{Abstract}

Despite the widespread interest in using and researching simulation in higher education, little discussion has yet to address a key pedagogical concern: difficulty. A 'sociomaterial' view of learning, explained in this paper, goes beyond cognitive considerations to highlight dimensions of material, situational, representational and relational difficulty confronted by students in experiential learning activities such as simulation. In this article we explore these dimensions of difficulty through three contrasting scenarios of simulation education. The scenarios are drawn from studies conducted in three international contexts: Australia, Sweden and the UK, which illustrate diverse approaches to simulation and associated differences in the forms of difficulty being produced. For educators using simulation, the key implications are the importance of noting and understanding (1) the effects on students of interaction among multiple forms of difficulty; (2) the emergent and unpredictable nature of difficulty; and (3) the need to teach students strategies for managing emergent difficulty.

Key words: simulation; professional learning; sociomaterial theory; difficulty; emergence.

\section{Introduction}

Simulation is an important and growing teaching and learning practice in professional and higher education. Its use has spread across a range of disciplines, including health and allied professionals (medicine, nursing, social work) that form the focus of this paper. Simulation is seen as a bridge to professional practice, providing authentic learning experiences under safe and controlled conditions (Kneebone et al. 2004). In turn, expectations are that simulation can enhance performance in subsequent 'real' practices, 
promoting safety, quality of care, and so on (Dieckmann and Krage 2013). In the health context, shortage of clinical placements further fuels the deployment of simulation across the curriculum (Kelly et al. 2014).

Although a centuries-old approach to pedagogy, simulation today plays historically new roles in higher education. Furthermore it is distinctive not only through the technologies and purposes associated with it, but for a strongly normative dimension. The related literature is characterised less by expansive debate, and more by attempts to reach consensus around common questions and to define approaches known to be effective. This is evident in prescriptions and protocols, and in research that seeks to define and measure effectiveness of standardised approaches in relation to pre-determined outcomes. For example, a cycle of briefing, scenario and debrief is rarely questioned, almost axiomatic as a pedagogic design feature (see Arthur et al. 2013). Within each phase there are strong norms, too, for example relating to the importance of authenticity in the scenario, or the need to emotionally debrief 'actors' before guided reflection on learning (Dieckmann 2009). This quest to connect routines of practice with better outcomes gives much of the literature a highly instrumental flavour.

In response, there have been several calls for more theoretical work in this area. Berragan (2011) argues theoretical groundwork has been neglected, and that enriching the theoretical base for simulation pedagogy is a pre-requisite if the field is to mature. Furthermore, Dieckmann et al. (2012) call for theorised, process-oriented analyses of current simulation practice. This paper extends a distinctive, contemporary strand of work that addresses precisely such concerns, based on what is termed a sociomaterial perspective (Fenwick 2012, 2014; Fenwick et al. 2011; Lee and Dunston 2011). Sociomaterialism emphasises the strong role of materiality in phenomena such as learning 
and pedagogy, and is applied by tracing changing, fluid relationships between people and the artefacts they engage with in particular practices.

To date, sociomaterial research has offered a radical rethinking of the philosophical underpinnings of simulation pedagogy in higher education (Hopwood et al 2014), and provided a fresh basis for analysing the pedagogic value and potential of existing practices (Ahn et al 2015; Rooney et al 2015). However, sociomaterialism has not yet been used as a basis to explore important questions about difficulty for learners in simulations. This gap is significant for both practical and empirical reasons. With regards to the former, we will show how difficulty-related concerns arise as key challenges for educators seeking to enhance simulation within higher education curricula. With regards to the latter, we will show how existing conceptions of difficulty within simulation literature reinforce reductive, linear models of instructional design and pedagogic practice.

\section{Difficulty as a practical pedagogic concern}

That educators should consider the difficulty of what they ask learners to do is widely accepted. More contested, are questions of how difficult particular activities should be, how to make them difficult, and in what ways they should be difficult. This applies to simulation-based teaching in higher education just as it does elsewhere. A systematic review of high-fidelity medical simulations found task difficulty level to be an important variable shaping the efficacy of learning (Issenberg et al. 2005). In this paper we refer to three different university settings in which difficulty is a key concern in the design and delivery of simulation-based learning. In each setting, the concern arises for distinctive reasons: cohort diversity in the Australian example, failure avoidance in Sweden, and calibration of assessment in the UK. All three share a common location within health 
professional education, covering nursing (Australia), medicine (UK), and interprofessional collaboration between nurses and medics (Sweden).

In Australia, frameworks for professional education and accreditation, combined with significant international higher education markets in the Middle East and South-East Asia, produce diversity in undergraduate nursing cohorts. Some students are school-leavers with no prior clinical experience, while others may have several years' experience in clinical positions for which tertiary qualifications were not required. Layered onto these differences are variations in the cultural location of prior experience: international students often find features of the Australian healthcare and educational systems unfamiliar and daunting (Kelly et al. 2014). Thus, educators in our Australian example view diversity as a key concern related to difficulty.

In Sweden, a growing focus for simulation in undergraduate health programs is interprofessional collaboration (Ahn et al. 2015). Here the aim is not to develop or demonstrate competence in particular technical skills, but rather to provide opportunity for students to enhance skills in working with colleagues from other professions. Simulations require students to work with cohorts from parallel programs in other professions, and are often framed to focus on features of scenarios that worked well. Clinical failure (e.g. the simulated patient dying) is often viewed as likely to undermine students' confidence and therefore undesirable (Johansson et al. 2014). This reflects a wider pedagogic norm of avoiding embarrassment and negative emotion, as we show in discussing relevant empirical literature below. Thus in our Swedish example, difficulty must be carefully pitched in order to provide valuable learning while avoiding tasks that are too hard and thus constitute a threat to simulation as a failure-free zone. 
Simulation can also help students to experience the simultaneity and multiple demands that characterise the complexities of practice on the wards. This is the case in our third example, from the UK. The particular setting uses volunteer patients in a multi-bed ward simulation that is managed for 20 minutes by the student doctor, and incorporates formal assessment and self assessment. The complexity level is high. Our discussion so far does not provide an exhaustive account of the pedagogic exigencies surrounding simulation practices in higher education. However it has explained why difficulty is an important issue, and showed how these reasons vary in their emphasis according to issues such as cohort diversity and contrasting pedagogic intentions. We will now turn to discuss how difficulty has been conceived within the research literature on simulation in higher education.

\section{Difficulty as an empirical concern in the literature}

Reviewing meta-analyses of intervention studies, we found that that difficulty has been addressed in relation to: cognition and psychomotor skills, desirable features of pedagogic design, intended learning outcomes of scenarios, and the learning of collaborative skills (Issenberg et al 2005; Cook et al. 2011, 2013). While helpful in informing instructional design, particularly with a view to developing protocols, these foci fail to explore the problem of difficulty in relation to simulation-based teaching and learning as it actually happens. It overlooks the granular, process-oriented quality that Dieckmann et al. (2012) call for. This paper addresses this shortcoming, but first we show how understandings of difficulty from broader educational theory have been taken up in the context of simulation in higher education. These provide an important point of contrast with the sociomaterial perspective offered in the present analysis. 
Ebbinghaus' (1885/1913) concept of the learning curve has framed a substantial body of work on simulation. Traces of this idea are evident in contemporary simulation education literature (Issenberg et al. 2005; Cook et al. 2011, 2013). The learning curve describes how fast individuals learn information, and is seen as one way of deciding the difficulty of a given task. After the first repetition, the sharpest increase of the curve occurs but then gradually evens out as less and less new information is retained after each repetition. As a framework for conceiving and designing-in difficulty, it remains common where the focus is on learning particular psychomotor skills (e.g. endoscopy, bronchoscopy, laparoscopy). Here, difficulties are conceptualised in relation to the mastery of discrete psychomotor skills by the individual learner (e.g. Chaudhry et al. 1999; Howell et al. 2007; Källström et al. 2010; Maschuw et al. 2011).

Another concept that has gained traction in simulation pedagogic research is cognitive load, drawing from developments in cognitive psychology (Sweller, 2003; Sweller et al. 2011). The imposed cognitive load is dependent on the number of elements with which the learners must deal simultaneously. In simulation education, cognitive load may be managed in two directions. Simple (low-load) tasks such as routine procedures can be 'made harder' by introducing time pressures. Conversely, complex scenarios such as acute emergency situations that might overwhelm students can be brought to a manageable load level by removing or ignoring particular features (Issenberg et al. 2011). Cognitive load theory also underpins the now widely accepted view in simulation pedagogy that varying levels of difficulty are preferable (Issenberg et al. 2005; Sweller 2012). Assumptions are made that the range of difficulty can be managed to offer gradual increase, based on analysis of psychomotor or cognitive demands and calibration with an 'appropriate level of difficulty' (Motala et al. 2013). 
Dieckmann et al.'s (2012) descriptions of 'success factors' in simulation-based learning included chunking difficult concepts, managing emotional challenges (such as avoiding embarrassment), group dynamics, prior competence in using simulation technology, and conceptual understanding. All of these have a direct bearing on difficulty experienced by students. Prior experience, task difficulty and time pressure come together to produce experiences of confidence, certainty or their opposites (Yang et al. 2012). Underpinning such views are assumptions that difficulty is fixed in the way simulations are set up and in what students bring with them to the simulation in terms of prior knowledge and experience.

Reflecting the strong instrumentality in much existing research, associations between difficulty and intended learning outcomes are common. Outcomes are understood to reflect alignment between difficulty in the form of required acuity, and opportunity to engage in authentic situations. Learning outcomes of simulation depend on flow and plausibility, enabling students to suspend disbelief and perform in a realistic manner (Flanagan et al. 2004). Flow and plausibility imply that the simulation hits a particular level of difficulty governed by realism (too easy or too hard, and it feels unrealistic). But also implied here is the notion that stepping into the simulated world as if real can itself be a source of difficulty. These authors note that psychological challenges can trigger emotional engagement and aid the process of immersion in the 'as-if' world of simulation. Thus different forms of difficulty are understood to be connected.

Difficulty has also been discussed in specific relation to collaborative teamwork skills (e.g. McLaughlin et al 2008). Here, difficulty is described in terms of handling increasing levels of responsibility and high-risk clinical situations with increasing complexity regarding equipment, communications, ethics, and systems-based challenges where only a team 
can successfully prevent or manage deterioration of the patient (Patterson et al. 2013).

Ker et al (2006) specifically examine the possibilities and challenges of reflecting this richer complexity in ward simulation exercises, an argument which is developed in terms of new innovations and approaches by Ker and Bradley (2010). Difficulty here is seen less in terms of individual demands or capabilities, but more in terms of parallel sets of relationships between participants, on the one hand, and pieces of equipment on the other. This relational focus leads us to the sociomaterial approach that we propose in this paper.

\section{A distinctive theoretical approach}

Several contemporary perspectives on learning and practice share a common metaphor of emergence (Hager 2011). Activity can be shaped by intentions, equipment, social roles and norms, but these and any other prior forces do not have exclusive grip on what happens. Phenomena such as learning cannot be completely sewed up in advance, they emerge. The term 'sociomaterial' refers to a number of theories that occupy this space, including actor-network theory, complexity theory, and practice theory (Fenwick et al. 2011). The argument in this paper remains at a super-ordinate level, proposing the disruptive value of a sociomaterial approach as per general, shared tenets (not least, the idea of emergence), rather than being tied to specific concepts associated with particular versions of sociomaterialism. This extends a new body of work that has applied sociomaterial approaches to medical education more generally (Fenwick 2014), medical simulation (Fenwick and Abrandt Dahlgren 2015), the philosophical foundation of simulation pedagogy (Hopwood et al. 2014), development of agile learners through simulation (Rooney et al. 2015), and knowledge practices in scenario, observation and control spaces (Ahn et al. 2015). 
Approaches centred on the idea of emergence decentre individual human subjects as the unit of analysis, and instead explore phenomena such as learning from a relational point of view (Fenwick 2010, 2012, 2014). Thus a property, such as difficulty, would be not be conceived as residing in any particular feature (instructional design, piece of equipment, task skill), but rather in the relationship between them. This challenges a number of historically dominant assumptions about linear relationships (eg. between intention and outcome), and temporal sequencing (what may be specified in advance of an event or not) (Hager 2011; Hopwood 2016).

The existing literature draws on concepts that assume any particular simulation activity is difficult (or not) to a degree that is determined in advance. This would be contested from a sociomaterial point of view. If difficulty is to be understood fully we must look not only at what is built in, but at what actually happens. In doing so, sociomaterialists pay particular attention to physical objects (materiality). Given associations of simulation with elaborate technologies (including high-fidelity manikins used in health professional education), the literature on simulation pedagogy recognises material presences as key shapers of what unfolds. However these are often conceived in terms of technological affordances, or dimensions of authenticity - qualities that reside in particular objects.

A sociomaterial perspective suggests that the influence of materiality emerges as particular practices (such as caring for a deteriorating 'patient') are enacted. In other words, we cannot determine the role of simulation equipment by looking at the equipment itself, nor simply at the pedagogic designs informed by it. We have to follow the action. In this way, objects are understood not just as tools used, enabling or constraining particular practices, but as forces, capable of demanding action, directing attention. This force is not internal but a property of entanglement with social phenomena. Sociomaterialism leads us 
to trace dynamic relationships between objects and intentions, meanings, interactions and emotions (Fenwick et al. 2011, Fenwick 2014).

Thus in the discussion that follows, we reflect on simulation pedagogies as they unfolded, seeking to understand this key aspect of higher education as an emergent phenomenon. We focus on shifting relationships between the social and material, considering what these relationships produce in terms of specific actions, habitual practices and learning. This renders us open to tracing unexpected and unintended features, including learning outcomes. This addresses Bligh and Bleakley's (2006) criticism of approaches that become overly occupied either with skills and performances, or 'technological fascination' prompted by seductive claims offering control of programmable events. Instead of asking 'How difficult is this scenario (as designed)?, we ask 'How does difficulty emerge, and what are the pedagogical implications of this?'.

\section{Empirical reference}

We draw on three case study scenarios, documented as part of separate but coordinated studies. The scenarios share relevant common features, but also contribute important differences. Two make use of high-fidelity manikins in non-assessed learning, while the third is based on role-play in the context of formal assessment. Table 1 below outlines key points of difference between the three scenarios. It also provides details of the wider empirical work from which each case study is drawn. Further methodological information is available elsewhere (Ahn et al 2015; Hopwood et al 2016; Kelly et al 2016; Nystrom et al In press a, b; Rooney et al 2015).

[Insert Table 1 here] 
The comparisons made below relate to the selected scenarios, and are not representative of approaches in particular institutions or countries, although we point to wider features that they illustrate where relevant. Our purpose is not to report findings, but to use empirical references to demonstrate the disruptive value of a sociomaterial perspective.

\section{Discussion}

We will now discuss each scenario in turn, showing how difficulty emerges through relationships between social and material aspects. Our argument is that difficulty cannot be fully fixed in advance or controlled by the educator. We consider the pedagogical implications arising across the three scenarios in the conclusions.

\section{Australia}

In this the conundrum highlighted to us by educators concerns offering simulation to cohorts with a very broad range of prior clinical experience, coupled with significant variation in cultural background (for a full description, see Rooney et al 2015). This complexity is intensified because the sequencing of simulation in relation to clinical placements within the overall degree is not uniform. Some students have just returned from placements, others are about to do theirs. What emerges in our discussion are issues relating to taking on unfamiliar roles; and managing what is attended to or not in the simulation.

At the start an experienced enrolled nurse occupies herself purposefully giving handover, she moves with confidence, linking verbal history to visible and tactile features of the patient. Meanwhile a school leaver stands awkwardly, adjusting posture and gaze with no clear focus, showing no synchrony with the handover being given. Moments later, confusion arises as an international student mishears the acting doctor, struggles to find 
the equipment she thinks is needed, and does not ask for help or clarification. This was attributed in debrief to shyness and embarrassment. Later still, a student designated as team leader remains quiet and stands at a distance, unsure of what to do or say, while another who has seen similar episodes in his clinical placement, takes up the leadership role.

Difficulty emerges as particular students, with different embodied histories to draw on and responses in the moment, interact with a scenario. While the scenario may be standardized, what students confront is not: the need to rescue the international student, or step in for the mute team leader emerge from a unique and unpredictable set of relationships. Difficulty for these learners is a fluid phenomenon, unstable and both individual and social, cognitive, bodily and material.

One distinctive feature of the Australian scenario is the allocation of students to team leader and registered nurse roles. By definition these lie beyond the scope of any student's prior direct experience, although students may have watched professionals in these roles while on placements. Some students were thus asked to step into their future selves, performing tasks and roles for which they have not yet been prepared. This is quite different from difficulty that arises through previously separate or isolated tasks being integrated in a single situation, or rendered challenging through temporal intensity. Here, it is a kind of meta-difficulty that is being simulated: not any particular psychomotor procedure or cognitive task, but the difficulty of doing what you don't know how to do. This is an inescapable feature of professional work after graduation.

Arguably there are valuable learning outcomes here, concerning the skills and confidence to cope with the unknown (see Rooney et al. 2015), however such pedagogic intentions sit 
uncomfortably with approaches that are protocol-driven, linked to pre-specified and measurable outcomes.

Finally we note how difficulty was 'managed out' of the emerging Australian scenario. The patient had multiple injuries and burns on his arm, resulting from a road traffic accident. Numerous times during the scenario, students touched the arm, for therapeutic reassurance, when giving injections, or accidentally leaning on it. In 'real' life this could cause pain to the patient, but the tutor did not raise this in the moment or in debrief. To do so might distract students unnecessarily from other features of the simulation, and make fluid performances around the bedside more difficult (see Flanagan et al. 2004). A potential for difficulty emerged here but was not activated. Hence by tracing what happened we can see a crucial role for tutor discretion and judgement, in-the-moment, in shaping difficulty. Dieckmann and Krage (2013) discuss 'variable-priority-training' in which certain features are included in scenario design. The example above shows how variance in priority emerges and thus requires ongoing monitoring and response by a tutor.

\section{Sweden}

In the Swedish example (for a full description, see Ahn et al 2015), the simulation involves medical and nursing students in their last semester, just prior to graduation. The stated learning objectives of the simulation are to practice interprofessional collaboration in an acute situation with a deteriorating patient after a traffic accident. In this setting a (more implicit) normative value of confidence building and failure avoidance shapes both the setup of the scenario, but also the way tutors respond to what develops within it. The tutor confirmed that the manikin is 'not allowed to die'. 
Emerging difficulties for students relate to organising team roles and preparation, the deteriorating medical conditions, and to an unplanned change in materialities of the simulation set-up. These arise through changing relationships among students, and between them, the manikin and other equipment.

Difficulty first arises when the trauma coordinator exits the room, having told students they need to prepare for the imminent arrival of an unconscious patient. Although the students had knowledge of their pre-assigned roles, this situation requires them to self-organise as a group and to consider what readiness involves. The students are not told what exactly needs to be done nor how to accomplish this. The dilemma is resolved when one student nurse takes on a leadership role, assigning immediate 'readiness' duties to her colleagues, coordinating the necessary material preparations (such as donning of gloves and plastic aprons), and prompting her peers to position themselves in a bodily arrangement ready to receive the patient.

Once the scenario is in full swing, a sound of the patient vomiting is triggered from the control room. Students recognise quickly that standard procedure in this instance is to turn the patient onto her side. This decision is relatively straightforward, but it presents a complex set of social and material demands. Some ongoing activities have to be attuned to the movement, as for the nurse responsible for the patient's catheter, who has to ensure it remains secure throughout the movement. To do so, she has to anticipate the timing, direction and speed of the turning, which is determined by the other students. The need to turn triggers some changing roles, as for the student who stands by the patient's head, and gives vocal directions to coordinate her colleagues ("We're turning on three. One, two, three"). She also has to ensure the neck is protected and supported throughout the procedure. Meanwhile, another student re-attunes the material environment, grabbing a 
bowl to catch the expected vomit. Thus a familiar change in patient condition is a catalyst for interlinked forms of difficulty to emerge. This account decentres the individual subject, seeing difficulty as originating in changing relationships between people and the material world. However, as our illustration shows, these difficulties, of course, have particular meaning and implications for individual students.

Later, the materialities of the simulation change in an unplanned way. The team notices the lack of vital signs displaying on the monitor, and the absence of detectable breathing from the manikin. Responding to these demands, signalling a near-death patient, the team begin resuscitation procedures. They arrange themselves, their actions, and relevant equipment in a manner appropriate in response to cardiac arrest. However the tutor stepped in and prompted the students to ignore the visual display and continue with their previous intervention as if the patient maintained a steady heart rate. The change in vital signs in fact resulted from accidental removal of the power source for the manikin and monitor. In this moment there was no way for the tutor to intervene to ensure the patient would respond to their appropriate clinical intervention and come back to life. Left uninterrupted, the students would have performed clinically appropriate actions decoupled from any associated simulator response. Furthermore, time constraints closed off options available to the tutor to extend the scenario or the debrief to adequately address the implications that would arise had the students gone further in their resuscitation (Nystrom et al In press a). Difficulty had reached 'impossible' levels within the norms of patient survival, and within the affordances of curricular arrangements.

These three emergent difficulties share some important features. The team has to define the situation, recognise and respond to newly arising needs or demands within the scenario, always aware of the risk of a fatal outcome (see Nystrom et al In press b). The 
changing manikin demands particular responses. These responses bring further challenges related to the use of protocols and equipment for acute trauma life support, noticing relevant signs of deterioration, and planning and requesting specialist assistance. Implicit norms buffering against failure and favouring confidence become visible in how the scenario is played out as the medical condition of the manikin deteriorates.

UK

This particular scenario differs to the Australian and Swedish examples because one student doctor must work with six 'patients' simultaneously in a multi-bed living ward, played by volunteer actors instead of manikins, and because formal assessment using direct observation of procedural skills is employed. The scenario including patient conditions, issues that emerge, and interruptions are derived from actual situations experienced by student doctors in hospital wards. Further details and points of contrast are provided in Table 1. The scenario aims to develop and assess students' capabilities more in managing situations than in completing tasks: prioritising patient urgency, multi-tasking, delegating appropriately, and making safe decisions. Thus the director of the simulation centre oversees the scenarios, with a remit to ensure a reasonable balance of difficulty with capability: challenge without excessive stress. But what is difficult for students may be different to what educators design and calibrate as difficulty. Students must cope with a range of material demands posed by the patients' bodies but they also encounter for the first time many, almost mundane material difficulties. Students display hesitation and awkwardness managing equipment in the small ward cubicles, as well as manoeuvring simulated body parts, sometimes misplacing medical charts. 
Difficulty also results from the student's own actions or neglect of important interventions. For instance, although the patient's breathlessness may increase while the doctor takes his history, the doctor doesn't stop to administer oxygen or nebulized salbutamol before she is called away to an emergency in the next cubicle. The breathless man deteriorates more quickly and the doctor is called back, now juggling two urgent situations simultaneously. This difficulty has emerged as a result of prior student inaction: it is not simply an effect of what was designed. This process takes varied forms, including when too many tasks are delegated to the nurse, who later becomes unavailable when needed.

Interestingly what is emerging here is an opportunity to explore the importance of attunement in learning medical practice (Fenwick 2014): attending through listening and sensing as well as observing, and attending to what may seem insignificant or mundane. This connects with 'situation awareness' (Wright et al. 2004), but concerns the ability not only to respond, but to anticipate, and to discern how one's activity is affecting the changing system. This entanglement of individual and extra-individual, social and material, and the complex causalities become visible through a sociomaterial perspective, which decentres the individual subject and opens up complex temporalities of action. From this standpoint we see how decisions that would not ordinarily be difficult for the student become very difficult. She may find herself struggling with procedures that she has performed successfully many times before, such as taking a patient history. A kind of overload is produced, sociomaterially rather than just cognitively.

Materiality does not only produce and expand difficulty, it also can help to settle and focus the student. Some use the material space to detach themselves, removing their bodies from the immediacy of practice and the pressure to act under scrutiny, creating space and time to re-balance their thinking. Others walk to the table at the foot of the bed and gaze at 
the patient chart for several minutes, or move to another cubicle where a patient is asleep. This touches upon learning that is particularly emphasized in this simulation centre: how to attune to and manage the ways that one's emotions are affecting one's own practice as well as the emerging materiality of the system. This includes novice doctors learning the signs that their stress is making them unsafe: causing them to take shortcuts, miss important cues, or make preventable mistakes. It includes understanding what difficulties are most difficult for them, and why. It also includes doctors adopting an active responseability within changing sociomaterial relationships, not trying to assert control but not giving up all control to each demand that arises. Difficulty of these forms is a far cry from the forms assumed, designed in, controlled and measured that typify dominant modes of thinking.

\section{Conclusions}

Having examined how difficulty emerges through relationships between social and material features of simulation in three different contexts, we will now look across these to consider the pedagogical implications that arise from such a 'sociomaterial' perspective.

First, the discussion affirms the relevance of difficulty as a central issue in simulation pedagogy: whether in group scenarios with high-fidelity manikins, or complex combinations of actors and equipment for assessment, the simulated nature of the process brings questions of difficulty to the fore. The very essence of simulation - merging elements of real and artificial, scripted and unscripted - produces a difficulty in a wide range of forms, making difficulty even more worthy of our attention. 
Prior simulation research has begun the process of mapping out kinds of difficulty, pointing to issues of cognitive overload (Young 2014; Issenberg et al. 2011), emotional demands (embarrassment in performing in front of others, making mistakes etc; (e.g. Mikkelsen Kyrkjebø et al. 2006), and technical demands (knowing how to work and work with various pieces of equipment and techniques (e.g. Munz et al. 2007). The advantage of our approach is that it folds all such forms of difficulty into the process of examining unfolding relationships between the performers (social) and what they are performing with (material). Rather than starting from a priori concepts that place boundaries around where difficulties lie, we trace how difficulties play out as simulation activities unfold.

As a result, our view of difficulty is transformed, with radical implications for simulation educators and pedagogic design. The separation of difficulty as of one kind or another breaks down in this view: there is no cognitive overload at one moment for one person, and emotional strain later, for someone else. Difficulties amplify, perhaps compounding each other, but perhaps also mitigated by the responses of others within the wider sociomaterial milieu. The precise combinations of difficulties, their timing, endurance and legacy throughout the scenario cannot be fixed in advance. While we can 'feed in' some aspects of difficulty, the experience of and response to difficulty is always an emerging phenomenon, both individual and collective, social and material.

While various forms of difficulty might be designed in or anticipated, they cannot be controlled by a tutor. Does this mean we should simply abandon the attempt to manage difficulty? Not at all. What this means is that questions of difficulty are not 'sewn up' when the scenarios are developed, when students are allocated to roles, or when the action starts. This places the educator in a crucial role, monitoring difficulty as it emerges and perhaps intervening to support students where multiple difficulties coincide and amplify. 
This is important whether the purpose is purely formative (as in the Australian and Swedish examples), or whether there are formal assessment criteria applied to students' performances (as in the UK example): a standardized scenario is not standardized in the same way as a pen-and-paper test. We acknowledge that the notion of emergence might be unsettling or confronting in a system where standardization of learning experiences, and particularly in assessment, is cherished ${ }^{1}$. A sociomaterial perspective does not rule out standardization, but requires us to think differently about what, exactly, can be standardized, how this might be accomplished, and how we might not just cope with emergent features, but embrace them as pedagogically valuable. Our paper does not fully address these issues, but raises them as important avenues for further theoretical and empirical enquiry, and critical reflection.

Simulation places demands on educators not only to notice varying forms of difficulty as they emerge in the moment, but to assess their effects. This then has implications for immediate debriefing, but also future revisions to scenario design or guidance given to students before the simulation. Perhaps most importantly, this approach provides a new way of thinking about how simulation has a bearing on future work performance and crucial issues of error reduction and patient safety. Conceiving difficulty in parcel, abstract forms such cognitive overload or emotional strain (etc.), points towards the thinking that goes into design before the simulation action unfolds, in an understandable, but we suggest ultimately doomed, quest for control that guarantees the best match between levels of difficulty presented and the particular students involved. Our sociomaterial approach inverts the thinking process, and instead traces difficulty as a product of design and response. It is surely here, in these fluid interactions between the social and material, where most valuable indicators of how well students are coping with the challenges, stresses and interruptions of clinical practice, are to be found. 
$[5,740$ words $]$

\section{Endnote}

${ }^{1}$ This insight came from one anonymous reviewer of this article, who helpfully commented, "I wondered if there was a more unsettling possibility that this sociomaterialist lens opened up, which was the radical incompatibility of experiences, a Heraclitean scepticism about ever stepping in the same river twice. If this is the case, how do we reconcile this vision to understandable concerns about fairness in assessment, especially in disciplines such as medicine that are quite naturally interested in maintaining standards?"

\section{Acknowledgments}

We are grateful to Dr Jean Ker, University of Dundee, UK, for helping to identify the importance of 'difficulty' in simulation, and for pointing us towards innovative practice in simulation education and assessment.

Disclosure statement: The authors declare that they have no relevant or material financial interests that relate to the research described in this paper.

\section{References}

Berragan, L. 2011. "Simulation: an effective pedagogical approach for nursing?" Nurse Education Today 31 (7): 660-3. doi: 10.1016/j.nedt.2011.01.019. 
Bligh, J. and A. Bleakley. 2006. "Distributing menus to hungry learners: Can learning by simulation become simulation of learning?" Medical Teacher 28 (7): 606-613. doi:

$10.1080 / 01421590601042335$

Chiniara, G., G. Cole, K. Brisbin, D. Huffman, B. Cragg, M. Lamacchia, D. Norman, and Guidelines Working Group Canadian Network For Simulation In Healthcare. 2013. "Simulation in healthcare: a taxonomy and a conceptual framework for instructional design and media selection." Medical Teacher 35 (8): e1380-95. doi:

10.3109/0142159X.2012.733451.

Cook, D. A., R. Hatala, R. Brydges, B. Zendejas, J. H. Szostek, A. T. Wang, P. J. Erwin, and S. J. Hamstra. 2011. "Technology-enhanced simulation for health professions education: a systematic review and meta-analysis." JAMA (Journal of the American Medical Association) 306 (9): 978-88. doi: 10.1001/jama.2011.1234.

Cook, D. A., S. J. Hamstra, R. Brydges, B. Zendejas, J. H. Szostek, A. T. Wang, P. J. Erwin, and R. Hatala. 2013. "Comparative effectiveness of instructional design features in simulation-based education: systematic review and meta-analysis." Medical Teacher 35: e867-e98. doi: 10.3109/0142159X.2012.714886.

Dieckmann, P. 2009. "Simulation settings for learning in acute medical care." In Using simulations for education, training and research, edited by P. Dieckmann, 40-138. Lengerich: Pabst. 
Dieckmann, P, and R Krage. 2013. "Simulation and psychology: creating, recognizing and using learning opportunities." Current Opinion in Anaesthesiology 26 (6): 714-20. doi: 10.1097/ACO.0000000000000018.

Dieckmann, P, S Molin Friis, A Lippert, and D Østergaard. 2012. "Goals, success factors, and barriers for simulation-based learning: a qualitative interview study in health care." Simulation \& Gaming 43 (5): 627-47. doi: 10.1177/1046878112439649.

Ebbinghaus, H. E. 1885/1913. Memory: A Contribution to Experimental Psychology. New York: New York Teachers College, Columbia University.

Ericsson, K. 2004. "Deliberate practice and the acquisition and maintenance of expert performance in medicine and related domains." Academic Medicine 79 (10) (suppl), S7081. doi: 10.1111/j.1553-2712.2008.00227.x

Fenwick, T. 2012. "Matter-ings of knowing and doing: sociomaterial approaches to understanding practice." In Practice, learning and change: practice-theory perspectives on professional learning, edited by P. Hager, A. Lee and A. Reich, 67-83. Dordrecht: Springer.

Fenwick, T. 2014. "Sociomateriality in medical practice and learning: attuning to what matters." Medical Education 48 (1): 44-52. doi:10.1111/medu.12295

Fenwick, T. and M. Abrandt Dahlgren. 2015. "Towards socio-material approaches in simulation-based education: lessons from complexity theory." Medical Education 49 (4): 359-367. doi:10.1111/medu.12638 
Fenwick, T, R Edwards, and P Sawchuk. 2011. Emerging approaches to educational research: tracing the sociomaterial. London: Routledge.

Flanagan, B, D Nestel, and M Joseph. 2004. "Making patient safety the focus: crisis resource management in the undergraduate curriculum." Medical Education 38: 56-66. doi: 10.1046/j.1365-2923.2004.01701.x.

Grierson, L. 2014. "Information processing, specificity of practice, and the transfer of learning: considerations for reconsidering fidelity." Advances in Health Sciences Education 19 (2): 281-289. doi: 10.1007/s10459-014-9504-x

Hatala, R, D Cook, B Zendejas, S Hamstra, and R Brydges. 2014. "Feedback for simulation-based procedural skills training: a meta-analysis and critical narrative synthesis." Advances in Health Sciences Education 19 (2): 251-72. doi: 10.1007/s10459013-9462-8.

Hopwood, N. 2016. Professional Practice and Learning: Times, Spaces, Bodies, Things. Dordrecht: Springer Press.

Hopwood, N, D Rooney, D Boud, and M Kelly. 2016. "Simulation in higher education: a sociomaterial view." Educational Philosophy and Theory 48 (2): 165-178. doi: 10.1080/00131857.2014.971403. 
Howell JN, et al. 2008. "Palpatory diagnosis training on the virtual haptic back: performance improvement and user evaluations". The Journal of the American Osteopathic Association 108: 29-36.

Issenberg, S. B., W. C. McGaghie, E. R. Petrusa, D. Lee Gordon, and R. J. Scalese. 2005. "Features and uses of high-fidelity medical simulations that lead to effective learning: a BEME systematic review." Medical Teacher 27 (1): 10-28. doi:

$10.1080 / 01421590500046924$.

Issenberg, S B, C Ringsted, D Østergaard, and P Dieckmann. 2011. "Setting a research agenda for simulation-based healthcare education: a synthesis of the outcome from an Utstein style meeting." Simulation in Healthcare 6 (3): 155-67. doi:

10.1097/SIH.0b013e3182207c24.

Isaranuwatchai, W, R Brydges, H Carnahan, A Dubrowski, and D Backstein. 2014. "Comparing the cost-effectiveness of simulation modalities: a case study of peripheral intravenous catheterization training." Advances in Health Sciences Education 19 (2): 21932. doi: 10.1007/s10459-013-9464-6.

Johansson, E., Lindwall, O. and Rystedt, H. 2014. "Experiences, appearances, and professional conduct: the use of video for instruction and reflection in post-simulation debriefings." Paper presented at the 53 ${ }^{\text {rd }}$ ICCA Congress, Antalya, 1-5 November.

Kelly, M., Hopwood, N., Rooney, D., \& Boud, D. 2016. “Enhancing students' learning through simulation: dealing with diverse, large cohorts." Clinical Simulation in Nursing, 12 (5): 171-176. doi:10.1016/j.ecns.2016.01.010 
Ker J. and P. Bradley. 2010. Simulation in medical education. In T. Swanwick, Understanding Medical Education: Evidence, Theory and Practice (pp. 164-180). Association for the Study of Medical Education.

Ker JS, EA Hesketh, F Anderson F et al. 2006. "Can a ward simulation exercise achieve the realism that reflects the complexity of everyday practice junior doctors encounter?" Medical Teacher, 28: 330-4.

Källström R., H. Hjertberg, and J. Svanvik. 2010. "Construct validity of a full procedure, virtual reality, real-time, simulation model for training in transurethral resection of the prostate." Journal of Endourology 24:109-15. doi:10.1089/end.2009.0114

Kelly, M. A., J. Forber, L. Conlon, M. Roche, and H. Stasa. 2014. "Empowering the registered nurses of tomorrow: students' perspectives of a simulation experience for recognising and managing a deteriorating patient." Nurse Education Today 34 (2): 724-9. doi:10.1016/j.nedt.2013.08.014.

Lee, A. and R. Dunston. 2011. "Practice, learning and change: towards a re-theorisation of professional education." Teaching In Higher Education 16 (5): 483-494. doi:10.1080/13562517.2011.580840

Maschuw, K, K. Schlosser, E. Kupietz, E. Slater, P. Weyers, and I. Hassan. 2011. "Do soft skills predict surgical performance?: a single-center randomized controlled trial evaluating 
predictors of skill acquisition in virtual reality laparoscopy." World Journal Of Surgery 35, (3): 480-486. doi:10.1007/s00268-010-0933-2

McLaughlin S, M. Fitch, D. Goyal, E. Hayden C. Kauh, T. Laack, T. Nowicki, Y. Okuda, K. Palm, C. Pozner, J. Vozenilek, E. Wang, J. Gordon; SAEM Technology in Medical Education Committee and the Simulation Interest Group. 2008. "Simulation in graduate medical education 2008: a review for emergency medicine." Academic Emergency Medicine 15 (11),1117-29. doi:10.1111/j.1553-2712.2008.00188.x

Motola, I., L. A. Devine, H. S. Chung, J. E. Sullivan, and S. B. Issenberg. 2013.

"Simulation in healthcare education: a best evidence practical guide. AMEE Guide No. 82." Med Teach 35 (10): e1511-30. doi: 10.3109/0142159X.2013.818632.

Mikkelsen Kyrkjebø, J., G. Brattebø, and H. Smith-Strøm. 2006. "Improving patient patient safety by using interprofessional simulation training in health professional education." Journal of Interprofessional Care 20 (5): 507-516. doi:10.1080/13561820600918200

Munz, Y., A. Almoudaris, K. Moorthy, A. Dosis, A. Liddle, and A. Darzi. 2007. "Curriculumbased solo virtual reality training for laparoscopic intracorporeal knot tying: objective assessment of the transfer of skill from virtual reality to reality." American Journal Of Surgery 193 (6): 774-783.

Norman, G. 2014. "Simulation comes of age." Advances in Health Sciences Education 19 (2): 143-6. doi: 10.1007/s10459-014-9507-7. 
Nystrom, S., J. Dahlberg, S. Edelbring, H. Hult, and M. Abrandt Dahlgren. In press a. "Debriefing practices in interprofessional simulation with students: a sociomaterial perspective." BMC Medical Education.

Nystrom et al. In press b. Enhancing simulation: a sociomaterial perspective on students' inteprofessional collaboration. Journal of Interprofessional Care.

Patterson, M., G. Geis, T. LeMaster, and R. Wears. 2013. "Impact of multidisciplinary simulation-based training on patient safety in a paediatric emergency department." BMJ Quality \& Safety 22 (5): 383. doi:10.1136/bmjqs-2012-000951

Rooney, D., N. Hopwood, D. Boud, and M. Kelly. 2015. "The role of simulation in pedagogies of higher education for the health professions: through a practice-based lens." Vocations and Learning 8 (3): 269-285 doi: 10.1007/s12186-015-9138-z.

Yang, H., C. Thompson, and M. Bland. 2012. "The effect of clinical experience, judgment task difficulty and time pressure on nurses' confidence calibration in a high fidelity clinical simulation." BMC Medical Informatics and Decision Making 12: 113. doi: 10.1186/14726947-12-113.

Wright, M., J. Taekman and M. Endsley. 2004. "Objective measures of situation awareness in a simulated medical environment." Quality and Safety in Healthcare 13 (1) (suppl), i65-i71. doi:10.1136/qshc.2004.009951 
Table 1 Details of the three scenarios in clinical simulation

\begin{tabular}{|c|c|c|c|}
\hline Loaction & Australia & Sweden & UK \\
\hline Profession(s) & Nursing & Nursing, Medicine & Medicine \\
\hline $\begin{array}{l}\text { Educational } \\
\text { context }\end{array}$ & $\begin{array}{l}\text { Final semester of } \\
\text { undergraduate } \\
\text { degree in nursing, } \\
\text { elective subject } \\
\text { focused on acute } \\
\text { care; no link to } \\
\text { assessment }\end{array}$ & $\begin{array}{l}\text { Final semester of } \\
\text { undergraduate degree in } \\
\text { nursing and in medicine, } \\
\text { subject focused on } \\
\text { acute care; no link to } \\
\text { assessment }\end{array}$ & $\begin{array}{l}\text { Final semester of } 5 \\
\text { year undergraduate } \\
\text { degree. } \\
\text { Performance } \\
\text { assessed by student } \\
\text { and two tutors: } \\
\text { pass/fail with } \\
\text { second chances. } \\
\text { Entire scenario } \\
\text { videotaped. }\end{array}$ \\
\hline $\begin{array}{l}\text { Activity } \\
\text { sequence }\end{array}$ & $\begin{array}{l}\text { Briefing (general then } \\
\text { technical), scenario, } \\
\text { debriefing }\end{array}$ & $\begin{array}{l}\text { Briefing (general then } \\
\text { technical), scenario, } \\
\text { debriefing }\end{array}$ & $\begin{array}{l}\text { Briefing, lectures, } \\
\text { scenario, self- and } \\
\text { tutor-assessment, } \\
\text { oral debriefing. } \\
\text { Further debrief if } \\
\text { student fails, before } \\
\text { second chance. }\end{array}$ \\
\hline Scenario & $\begin{array}{l}\text { Deteriorating patient: } \\
\text { cardiac arrest as }\end{array}$ & Deteriorating patient: & $\begin{array}{l}\text { Ward simulation - } \\
\text { six patients. Begins }\end{array}$ \\
\hline
\end{tabular}




\begin{tabular}{|c|c|c|c|}
\hline & $\begin{array}{l}\text { result of allergic } \\
\text { reaction to antibiotics }\end{array}$ & $\begin{array}{l}\text { Unconsciousness as a } \\
\text { result of head trauma in } \\
\text { a car accident }\end{array}$ & $\begin{array}{l}\text { with handover, then } \\
20 \text { minutes } \\
\text { managing ward. } \\
\text { Various } \\
\text { interruptions and } \\
\text { acute deterioration } \\
\text { of patient } \\
\text { conditions. }\end{array}$ \\
\hline Student roles & $\begin{array}{l}\text { Team leader, } \\
\text { registered nurse (x2), } \\
\text { triage nurse (hands } \\
\text { over), wife \& } \\
\text { daughter, patient } \\
\text { (voice); laboratory } \\
\text { (gives results of blood } \\
\text { tests via phone); } \\
\text { remaining students } \\
\text { observe }\end{array}$ & $\begin{array}{l}\text { Two medical students in } \\
\text { the roles of surgeon on } \\
\text { call (team leader) and } \\
\text { assisting colleague. } \\
\text { Three nursing students } \\
\text { in the roles of nurses in } \\
\text { the emergency room. } \\
\text { One registered nurse as } \\
\text { technical assistant in the } \\
\text { simulation room. } \\
5-6 \text { students as } \\
\text { observers in the } \\
\text { manoeuver room }\end{array}$ & $\begin{array}{l}\text { One student acts as } \\
\text { ward physician. } \\
\text { Tutor may act as } \\
\text { handover physician. } \\
\text { One registered } \\
\text { nurse as assistant } \\
\text { to student. Further } \\
\text { help is available via } \\
\text { telephone. } \\
\text { Interrupting roles } \\
\text { may include patient } \\
\text { family members, } \\
\text { delivery of test } \\
\text { results, etc. }\end{array}$ \\
\hline
\end{tabular}




\begin{tabular}{|c|c|c|c|}
\hline Tutor roles & $\begin{array}{l}\text { Lead brief and } \\
\text { debrief; plays } \\
\text { resident medical } \\
\text { officer (doctor) in } \\
\text { scenario }\end{array}$ & $\begin{array}{l}\text { Two medical doctors as } \\
\text { instructor and operator } \\
\text { in the manoeuver room. } \\
\text { Lead brief and debrief, } \\
\text { patient (voice), give } \\
\text { result of tests and } \\
\text { examinations, } \\
\text { Plays switchboard, x-ray } \\
\text { department via phone, } \\
\text { anaesthetist in scenario }\end{array}$ & $\begin{array}{l}\text { Leads briefing and } \\
\text { debriefing; plays } \\
\text { roles on ward and } \\
\text { on telephone as } \\
\text { needed; assesses } \\
\text { student; offers } \\
\text { follow up instruction. }\end{array}$ \\
\hline $\begin{array}{l}\text { Details of } \\
\text { empirical work } \\
\text { from which } \\
\text { case study } \\
\text { scenario is } \\
\text { drawn }\end{array}$ & $\begin{array}{l}\text { Observation and } \\
\text { video recording of } 10 \\
\text { scenarios, } 5 \text { in each } \\
\text { of } 2 \text { tutor groups; } 3 \\
\text { scenarios in one } \\
\text { class early in } \\
\text { semester and } 2 \text { in a } \\
\text { class at end of } \\
\text { semester. } \\
\text { Observation and } \\
\text { audio recording of } \\
\text { preparation and } \\
\text { debrief discussions } \\
\text { for each scenario } \\
\text { (see Rooney et al }\end{array}$ & $\begin{array}{l}\text { Three-site, multi-phase } \\
\text { study including } \\
\text { observation and video } \\
\text { recording; } 10 \text { video } \\
\text { recordings from each } \\
\text { site over several years, } \\
\text { including multiple } \\
\text { medical and nursing } \\
\text { cohorts (students } \\
\text { involved in two sites, } \\
\text { qualified professionals } \\
\text { only in the third site) } \\
\text { (see Ahn et al } 2015 \text {; } \\
\text { Nystrom et al In press } \\
\text { a,b) }\end{array}$ & $\begin{array}{l}\text { Observation and } \\
\text { video recording of } \\
12 \text { multi-ward live } \\
\text { simulation } \\
\text { exercises, } \\
\text { observation of tutor } \\
\text { debriefing sessions } \\
\text { with students, and } \\
\text { discussions of } \\
\text { videos and debriefs } \\
\text { with tutors (see } \\
\text { Fenwick and } \\
\text { Abrandt Dahlgren } \\
2015 \text { ). }\end{array}$ \\
\hline
\end{tabular}




\begin{tabular}{|l|l|l|l|}
\hline 2015; Hopwood et al & & \\
2016; Kelly et al & & \\
2016). & & \\
\hline
\end{tabular}


